\title{
Research on rural landscape design of Yili River Basin under the background of low-carbon Economic Development The example of Bayandai village
}

\author{
Wei Wei ${ }^{1, *}$ \\ ${ }^{1}$ Yili Normal University, YiNing, XinJiang, China
}

\begin{abstract}
With the deepening of One Belt, One Road Innitiative, Yili River Basin has also witnessed significant opportunities for rural tourism. Taking Bayandai village in Yili River Basin as an example, based on the local characteristic cultural resources, this paper discusses the rural landscape design methods with Yili characteristics, carries out systematic research of landscape culture, and displays the unique charm of rural tourism in Yili River basin with diversified landscape culture, so as to make it a banner of rural tourism in Yili River Basin, Boosting the reasonable development of low-carbon economy in border areas and promoting the level of tourism economy.
\end{abstract}

\section{Introduction}

As One Belt, One Road policy continues to push forward, rural tourism in Xinjiang has gradually shown a good momentum of development. Xinjiang tourism is an important industry of Local Development, taking the opportunity of vigorously developing tourism industry to promote the reasonable development of low-carbon economy in border areas and realize the win-win of environmental protection and income generation. Rural tourism, as an important measure to promote the coordinated progress between urban and rural areas and to promote rural income and poverty alleviation, has brought new channels for many people living in rural areas for a long time. As One Belt, One Road core area, the Yili River Basin of Xinjiang is known as "the south of the river beyond the mountains" because of abundant rainfall, abundant natural resources and good natural ecology. The development of its rural tourism is in the forefront of the whole region, displaying unique rural tourism characteristics. However, with the rapid development of rural tourism, many problems are exposed. Some rural infrastructure lacks design and unified landscape planning. Although they are unique tourism resources, they can not provide comfortable tourism facilities for tourists, which leads to the short time of many tourists staying in the countryside and poor tourism experience. In the same time, local economic development is slow, if any. [1] As an important part of the landscape, rural landscape plays an important role in attracting tourists. Unreasonable rural landscape also hinders the rural tourism industry to move forward to a higher platform.

For a long time, Yili River Basin has been viewed as the western frontier, tourists only staying in the original ecological natural landscape of snow mountain grassland, ignoring the rich and colorful cultural resources of Yili as a multi-ethnic gathering area. How to combine the two organically to form a new situation of attaching equal importance to natural resources and human history is an important problem to be solved at this stage.

In recent years, Yining municipal government is also focusing on building a diversified tourism landscape, forming a Kazanqi old city tourism area to show the Uygur culture and a six star street historical area to show the Russian culture. Compared with these historical districts, Bayandai village also has unique cultural characteristics. On the one hand, as the nearest village to Yining City, the geographical advantages give it better accessibility to rural tourism, while the local farmers maintain the original ecological working habits, which makes it have unique tourism resources. On the other hand, Bayandai village, as a place where Wang Meng, former Minister of Culture of the People's Republic of China, has lived in the countryside for many years, has deeply explored the cultural symbols of Bayandai village, which are characterized by "unity culture, novel culture, agriculture and animal husbandry culture, ethnic culture, and ancient city culture", making Bayandai village the first one in Yining City to collect lodging, play, entertainment, and food with the theme of suburban rural cultural tourism, cultural experience, patriotism education as one of the rural tourism complex. 


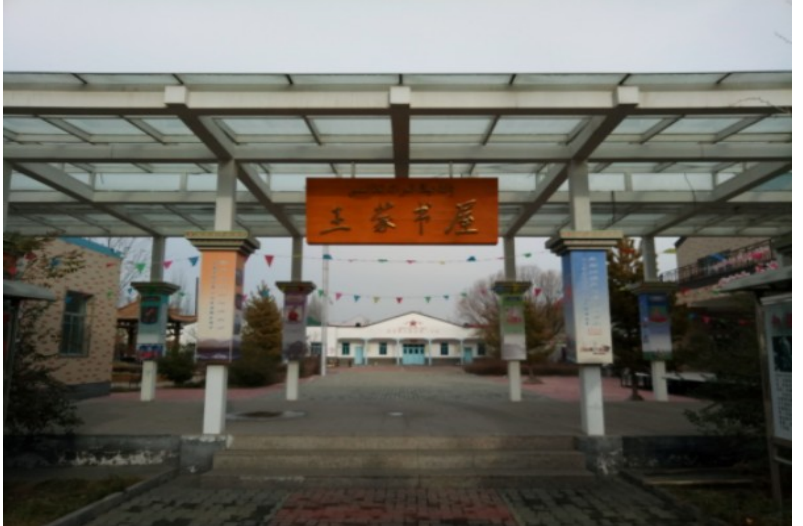

Fig. 1. Current situation of Wang Meng Library in Bayandai Village

\section{Analysis of the current situation of Bayandai Village}

Bayandai village is located in the western suburb of Yining City, which is an important area in and out of Yining City. At present, with the continuous development of Yining City, Bayandai village is close to the development zone of Yining City and has become the nearest village to the city. Bayandai village has also done some simple landscape design with the theme of Wang Meng's landscape here. For example: next to the canal along the street, a wooden cement arch bridge is erected at the exit of each household. A billboard built at the entrance of the village shows that the scenery here is unique. Wang Meng bookstore was set up in the village committee to convey cultural ideas.Posters with national characteristics are drawn on the wall along the street. Due to the lack of systematic planning, this series of simple design methods did not form a good tourism atmosphere, which did not play a significant role in promoting the rural tourism of Bayandai village.

First of all, the village only takes Wang Meng's novel culture as its propaganda theme, with single form and outdated display form. Lack of supporting tourism service facilities did not form a good tourism system and atmosphere. Secondly, it ignores the attraction of the unique original ecological scene display of suburban villages to urban residents. Finally, the lack of in-depth excavation and development of local rich tourism resources, the lack of a systematic tourism landscape node, of in-depth research on the richness and scarcity of tourism resources, are all to ba taken into consideration when we say that the touristical atmosphere is rather incoherent.

\section{Landscape culture excavation of Bayandai Village}

In view of the related problems found in the investigation process of Bayandai village, this paper makes an in-depth research and analysis. On the premise of developing rural tourism, this paper probes into the unique cultural connotations of Bayandai village, and strives to make it a boutique tourist attraction in the process of landscape design of the village.

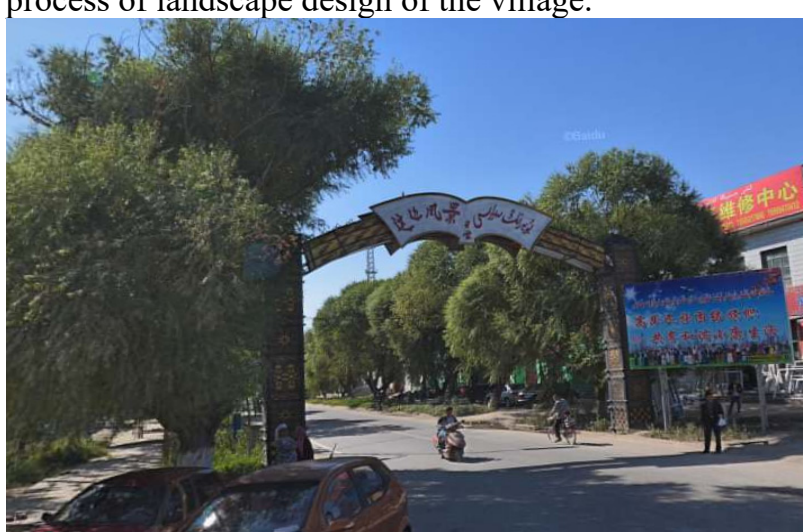

Fig. 2. Status quo of main landscape road in Bayandai Village

\subsection{Novel appreciation of culture}

Bayandai village, as a place where Wang Meng has lived for many years, has developed a profound friendship with the local Uygur, Kazak and other ethnic compatriots in the last century. Many characters have become the real materials of Wang Meng's novel scenery here. [2] These vivid characters give birth to a unique frontier culture. It is necessary to excavate and display in depth to form a unique brand of Bayandai village's novel cultural landscape. With the help of celebrity aura, it can create a novel cultural landscape village with the characteristics of Xinjiang. On the one hand, it plays a role in publicizing Bayandai village, on the other hand, it provides a good platform for the majority of literature lovers to exchange appreciation and discuss literary works together. Therefore, it has unique cultural value and tourism resources worthy of promotion and development.

\subsection{Culture of national unity}

For a long time, all ethnic groups in Bayandai village have lived and worked together and helped each other, a fact also noticed by the famous writer Wang Meng. During an important period of his life, he interacted with all ethnic groups and helped each other, making it a model of national unity. The culture of national unity is particularly prominent in Bayandai village. In the process of exchanges among various nationalities, the excellent stories of multi-ethnic exchanges are worth promoting and displaying, forming a good social influence and promoting the progress of national unity.

\subsection{Farming, animal husbandry and farming culture}

The Uygur people mainly focus on agricultural production activities, while the Kazakh people mainly focus on grazing. In addition, the unique Lavender planting industry in Ili region makes the suburb feel the pure natural rural cultural life become the desire of urban residents.Farming and animal husbandry culture as the daily life of farmers, if integrated into the form of 
tourism economy, on the one hand to contribute to the development of low-carbon economy, on the other hand, it can increase the income source of local farmers.

\subsection{Huining ancient city culture}

In 1766, Huining city was built in Bayandai village. It is one of the nine cities of Ili, with more than 2200 officers and soldiers stationed, of different nationalities. It is also known as "Huining Manying", commonly known as "laomanying". Nowadays, the old city of Huining is seriously damaged due to its long history, leaving only a few ruins of the city wall. How to better display the thick history and culture of the ancient city based on the landscape design of Bayandai village is worthy of indepth study and discussion.

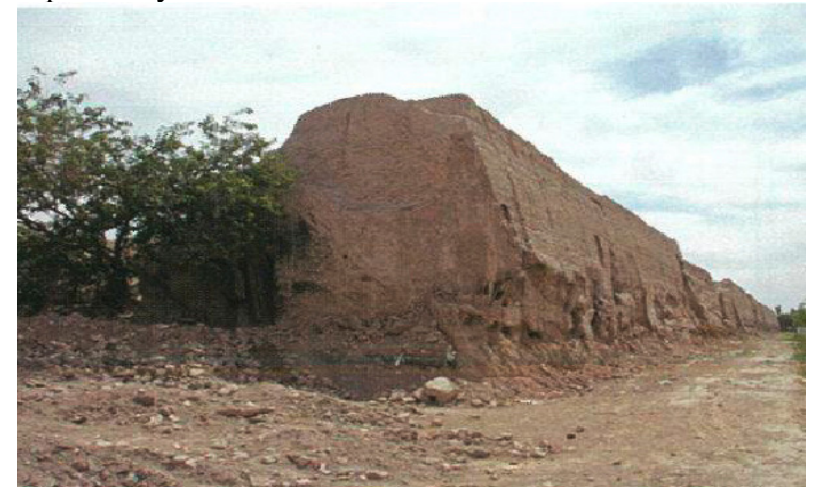

Fig. 3. The present situation of Huining ancient city

\section{Research on the Landscape Design Concept of Bayandai Village}

Through the excavation and analysis of the tourism resources culture in Bayandai village, we try to use the method of landscape design to carry out the systematic integration and landscape design planning of the excavated tourism resources culture and other items, mainly serving the tourism industry, to create a unique rural landscape culture in Ili Kazakh Autonomous Prefecture and contribute to the development of lowcarbon economy in the border areas.

\subsection{Improvement of residential architectural cultural landscape}

To develop rural tourism in the suburbs of the city, Bayandai village is located in the west of Yining City, close to the Development Zone, due to its prominent location advantages. In the village, the residential buildings are uniform, and the courtyard layout is reasonable. Every family has a variety of fruit trees, such as grapevine, apple, apricot and so on. The courtyard is surrounded in the center. Most of the peasant households have the conditions to set up rural hotels and hotels. However, in the process of investigation, it is found that the appearance of the houses still needs further design and renovation, and the decoration also needs to focus on renovation. [3] We should carry out personalized renovation for the houses along the street, form the "one household one policy" of the pavement along the street, create a diversified indoor and outdoor courtyard environment, and carry out the top-level design.

In Bayandai village, according to the scenery of Bayandai village described in the landscape here by Wang Meng, the former Minister of culture, and according to the famous description in the novel, the farmers who are suitable for the scene performance are selected from the locals and professional training is carried out. The live play is reproduced at a fixed time and times every week, to form a special tourism route with rural characteristics of Yili River Basin.

\subsection{Water landscape design with the theme of "south of the Yangtze River beyond the Great Wall"}

Bayandai village has two main canals on both sides of the main road, with good water landscape foundation conditions. [4] On this basis, further deepening design and transformation are needed. The existing ditch in the village is covered with cement, and the small bridge entering the house is also made of cement, with simple shape and no aesthetic feeling. One meter green belt is set aside at the edge of the original cement ditch, and various ornamental plants are planted to form a good road greening landscape form. The external walls of the houses built by farmers are improved artistically to form a good cultural and artistic atmosphere in the whole village. The abundant wood resources in the village are used to create woodcarving art landscape nodes.

\subsection{Agricultural leisure landscape design}

The main purpose of Bayandai village is to plant wheat. When the wheat is ripe, the waves of wheat are rolling, forming a good original ecological agricultural landscape. According to the actual situation, we can create a wheat field landscape integrating sightseeing, camping and agricultural experience. The wood corridor was set up on the wheat field to form a better viewing corridor. A circular wooden corridor one meter above the ground is set up above the wheat field, and the wooden platforms for visitors to have a picnic are connected by the corridor to form a unique viewing angle. Overlooking the wheat field, the whole wooden corridor is like a crown lying on the wheat field.

Build a paradise dominated by lavender. First of all, relying on the local specialty lavender, optimize the industrial structure, with systematization as the starting point, drive Bayandai village into a new stage of lavender industry development. Secondly, industrial extension should be carried out. Based on the primary lavender industry, deep processing derivatives of the secondary industry should be vigorously developed, and the tertiary industry should be actively promoted, such as planning lavender sightseeing agricultural park, and lavender picking Festival. Finally, the traditional lavender planting and picking is extended to the interactive mode of agricultural cultural landscape, showing all aspects of agriculture, forming a characteristic agricultural ornamental culture. 


\subsection{Landscape design of national unity culture}

Yili River Basin has been a multi-ethnic gathering area since ancient times. Taking Bayandai village as an example,there are more than ten different nationalities in the village, such as Han, Uygur, Kazak, Russian, Uzbek.Each ethnic village and culture blend with each other and have their own characteristics, forming a unique style of Chinese culture.

Take the existing village square as the main site to build the cultural square of national unity. [5] Wooden totem poles are built with different cultural characteristics of each nation and surrounded by the square, forming 56 national totem culture exhibitions. The design of the ground pavement is based on the five stars representing the motherland, which shows the meaning of 56 nationalities' unity and cooperation in the arms of the motherland family to create a better home. It also allows more local people to broaden their horizons, understand the cultural characteristics of different nationalities, and form a broad mind of tolerance and multiculturalism.

\subsection{The landscape design of ancient city ruins combined with patriotic education}

Huining ancient city is also known as "old Mancheng". During the reign of Emperor Qianlong, the Manchu and Mongolian officers and soldiers stationed here made great contributions to guarding the stability of the border and maintaining the reunification of the motherland, and Lin Zexu's inspection and construction in the ancient city was also an important part of the exhibition. Therefore, the establishment of Huining ancient city cultural exhibition hall here, on the one hand, shows the ancient city building mode and city culture in the ancient border areas, on the other hand, it also focuses on carrying forward the noble patriotic feelings of ancient minority officers and soldiers who are thousands of miles away from home to protect the border and defend the country. Their great patriotic spirit for the peace of the border areas and the security of the motherland is worth promoting and affirming.

The exhibition hall centered on Huining ancient city site. It not only shows the profoundness and profundity of Chinese architectural culture, but also displays the patriotism spirit of a group of ancient national heroes mainly Lin Zexu. It shows his great contribution in maintaining the stability of the border and promoting the development of Ili from various angles, educates people with the spirit of celebrities, and forms a patriotic education base with the ancient city culture. While feeling the rural civilization, we can also be influenced by the profound architectural history, culture and patriotism.

\section{Conclusion}

The implementation of rural landscape design provides an important guarantee for the construction of World Tourism Valley in Yili River Basin. We use raw natural materials in our design. It also provides a new attempt for the development of low-carbon tourism economy in Ili Kazakh Autonomous Prefecture. It is necessary to adhere to the concept of sustainable development and innovate design methods. The development of rural civilization will also further promote the overall progress of regional social landscape. The organic integration of rural tourism and characteristic landscape design, and the collaborative participation of government departments, villagers and tourists will create a diversified tourism process in Bayandai village, and promote the vigorous development of rural tourism in the suburbs of the city. At the same time, patriotism culture, national unity culture, novel culture and other educational landscape node construction will also enable tourists to deepen the cultural conservation of positive energy conveyed in the tourism landscape in the process of playing. The main goals are to culturally integrate borders into the grassroots, to promote the development of tourism and the improvement of rural style in the Yili River Basin, to promote the economic development of border areas, and to contribute to the building a moderately prosperous Chinese society.

\section{Acknowledgments}

This paper is one of the periodic results of the project "One Belt And One Road" Research Institute of Yili Normal University "Research on Rural Landscape Design of Yili River Basin under the Background of" One Belt And One Road "-- Taking" Bayandai Village "in Yining City as an Example" (YDYL2020YB013).

\section{References}

1. Song JI. (2020) Research on the effective connection between rural landscape planning and rural ecological livability . J. Rural areas. Agriculture. Farmers.,12:10-12.

2. Zhang L. (2020) Research on Conservation and Renewal Strategy of Qingdao Li Yuan under the Guidance of Vitality and Renewal -- A Case Study of Guangxingli. J. Architecture and Culture., 12:111-113.

3. Zhi YX. (2020) Analysis on the Expression of Regional Culture in the Construction of Beautiful Village -- A Case Study of the Design of Rural Landscape Enhancement in Baimaitang Village. J.Modern Horticulture.,43:171-173.

4. Li J. (2020) Rural Landscape Design Based on the Protection of Rural Landscape . J. Shanghai Textile Science and Technology.,48:70-71.

5. Deng CF, Lu JW. (2021)Study on the protection and renewal of historical and cultural blocks - Taking Dongxi Lane, Zhengyang road, Guilin as an example. J. Residential Technology.,41:38-41. 